\title{
Finite Element Discretization and Simulation of Groundwater FlowSystem
}

\author{
K. R. Adeboye ${ }^{1}$, M. D. Shehu ${ }^{2}$, A. Ndanusa ${ }^{3}$ \\ ${ }^{1,2,3}$ (Department of Mathematics/Statistics, Federal University of Technology, Minna, Nigeria)
}

\begin{abstract}
This paper considered a two dimensional flow in $x$ and $y$ coordinate system and derived a NonHomogenous Laplace Equation for groundwater flow using Darcy's equation which form the basis for the finite element discretization process. By discretizing the Hydraulic Conductivity and Piezometric Head in the $x y$ direction, a flow direction vector of the groundwater system is obtained.
\end{abstract}

Keywords -Finite element method, Hydraulic conductivity, Groundwater flow, Piezometric head, Laplace equation

\section{Introduction}

Groundwater is water located beneath the ground surface. A unit of rock or sediments is called an aquifer when it can yield a usable quantity of water [1]. The depth at which soil pore spaces and voids in rock become completely saturated with water is called the water table [2]. Groundwater is a vital resource in our environment.It replenishes our streams, rivers, habitats[3]. However, groundwater is highly vulnerable to contamination from septic tanks, agricultural runoff, highway, pipe leaks, spills, industrial activities and improper disposal practices [4]. In [5], Kamkar-Rouhani stressed that in mining excavation as well as many engineering operations, groundwater situation in an area under operation should be characterized and considered in the design of the operation. Experience has shown that most important organs of the human body are not seen outside. For example, blood and the heart that pumps it are not visible, yet they are very important [6].

\section{Model Formulation}

We employthe method of space $(x, y)$ discretization of the groundwater flow, where the computational domain is divided into finite element mesh connected at nodes $i, j, k$.Our governing equation is the Darcy's equation given by [7] thus:

$$
Q_{i}=-k_{i j} A\left(\frac{\partial h}{\partial x_{j}}\right)
$$

Where;

$\begin{array}{lll}Q & = & \text { Flow rate } \\ A & = & \text { Flow Cross Section Area } \\ h & = & \text { Piezometric Head } \\ k & = & \text { Hydraulic Conductivity. }\end{array}$

According [8],

$$
Q=A v
$$

Substituting equation (2.2) into (2.1) we have,

$$
A v=-k_{i j} A\left(\frac{\partial h}{\partial x_{j}}\right)
$$

Where, $v=$ Flow velocity

That is,

$$
v=-k_{i j}\left(\frac{\partial h}{\partial x_{j}}\right)
$$

We now express equation (2.4) in a layered coordinate system in the directions $\xi$ and $\eta$. 


$$
v_{\xi}=-k_{\xi} \frac{\partial h}{\partial \xi}
$$

and

$$
v_{\eta}=-k_{\eta} \frac{\partial h}{\partial \eta}
$$

Where; $v=$ Flow Velocity, $h=$ Piezometric Head, and $k=$ Hydraulic Conductivity.

In matrix notation, equations (2.5) and (2.6) can be expressed as:

$$
\left[\begin{array}{l}
v_{\xi} \\
v_{\eta}
\end{array}\right]=-\left[\begin{array}{cc}
k_{\xi} & 0 \\
0 & k_{\eta}
\end{array}\right]\left[\begin{array}{l}
\frac{\partial h}{\partial \xi} \\
\frac{\partial h}{\partial \eta}
\end{array}\right]
$$

Equations(2.5) and (2.6) expressed in the Global $x-y$ coordinate system takes the following form:

$$
\begin{aligned}
& v_{x}=-k_{x x} \frac{\partial h}{\partial x}-k_{x y} \frac{\partial h}{\partial y} \\
& v_{y}=-k_{y x} \frac{\partial h}{\partial x}-k_{y y} \frac{\partial h}{\partial y}
\end{aligned}
$$

Combining equations (2.8) and (2.9) with the following equation given by [8]

$$
\frac{\partial v_{x}}{\partial x}+\frac{\partial v_{y}}{\partial y}=0
$$

(2.10)

weobtain the equation for groundwater flow as

$$
k_{x x}\left(\frac{\partial^{2} h}{\partial x^{2}}\right)+2 k_{x y}\left(\frac{\partial^{2} h}{\partial x \partial y}\right)+k_{y y}\left(\frac{\partial^{2} h}{\partial y^{2}}\right)=0
$$

For the Aquifer under consideration (isotropic soil),

$$
k_{x x}=k_{y y}=k
$$

$$
\text { (2.12) }
$$

and

$$
k_{x y}=k_{y x}=0
$$

Equation (2.11) reduces to:

$$
\frac{\partial^{2}}{\partial x^{2}}(k h)+\frac{\partial^{2}}{\partial y^{2}}(k h)=r
$$

Equation (2.1) is equivalent to:

$$
\frac{\partial}{\partial x}\left(k \frac{\partial h}{\partial x}\right)+\frac{\partial}{\partial y}\left(k \frac{\partial h}{\partial y}\right)=r
$$

Where $r=$ Potential Head Value.

Equation (2.15) is a Non-Homogeneous Laplace's equation for groundwater flow.

We now compute the solution for the Hydraulic Heads at the nodes of the triangular element of the domain under consideration.

In line with equation (2.15) we consider the equation;

$$
\frac{\partial}{\partial x}\left(k \frac{\partial u}{\partial x}\right)+\frac{\partial}{\partial y}\left(k \frac{\partial u}{\partial y}\right)=r
$$




$$
R_{\Omega}(x, y)=\frac{\partial}{\partial x}\left(k \frac{\partial u}{\partial x}\right)+\frac{\partial}{\partial y}\left(k \frac{\partial u}{\partial y}\right)-r \quad \text { in } \Omega
$$

Where, $\Omega$ =Domain under consideration, $r=$ Potential Head values at the Nodes, $R_{\Omega}=$ Residual function, and $u=h=$ Piezometric Head.

We introduce an arbitrary function

$$
w_{\Omega}=w_{\Omega}(x, y)=w \text { in } \Omega
$$

Where, $w_{\Omega}=$ weighting function.

Equation (3.17) takes the form;

$$
\int_{\Omega} w\left[\frac{\partial}{\partial x}\left(k \frac{\partial u}{\partial x}\right)+\frac{\partial}{\partial y}\left(k \frac{\partial u}{\partial y}\right)-r\right] d \Omega=0
$$

After integration by parts and use of divergence theorem equation (2.19) is written as

$$
-\int_{\Omega}\left[\frac{\partial w}{\partial x} k \frac{\partial u}{\partial x}+\frac{\partial w}{\partial y} k \frac{\partial u}{\partial y}+w r\right] d \Omega+\int_{\partial \Omega} w k\left[\frac{\partial u}{\partial x} n_{1}+\frac{\partial u}{\partial y} n_{2}\right] d \Gamma=0
$$

The projection of the gradient of $u$ in the direction of the outward unit normal $\mathbf{n}$ is given by:

$$
\frac{\partial u}{\partial n}=\frac{d u}{d \mathbf{x}} \cdot \mathbf{n}=\frac{\partial u}{\partial x} n_{1}+\frac{\partial u}{\partial y} n_{2}
$$

In line with equation (2.21), equation (2.20) can be written as

$$
-\int_{\Omega}\left[\frac{\partial w}{\partial x} k \frac{\partial u}{\partial x}+\frac{\partial w}{\partial y} k \frac{\partial u}{\partial y}+w r\right] d \Omega+\int_{\partial \Omega} w k \frac{\partial u}{\partial n} d \Gamma=0
$$

For a homogenous boundary system (Domain under consideration), equation (2.22) can be expressed operationally as follows:

$$
B(w, u)+(w, r)=0
$$

Where,

$$
u=\left\{u \in H^{1}(\Omega)\right\}
$$

$$
w=\left\{w \in H^{1}(\Omega)\right\}
$$

$$
H^{1}(\Omega)=\text { Sobolev Space }
$$$$
B(w, u)=\int_{\Omega}\left(\frac{\partial w}{\partial x} k \frac{\partial u}{\partial x}+\frac{\partial w}{\partial y} k \frac{\partial u}{\partial y}\right) d \Omega
$$

We have that

$$
(w, r)=\int_{\Omega} w r d \Omega
$$

$$
\begin{aligned}
& u_{h} \in U_{h} \\
& (2.28) \\
& w_{h} \in W_{h} \\
& (2.29)
\end{aligned}
$$

In line with equation (2.28) and (2.29), equation (2.23) can be written as; 


$$
B\left(w_{h} u_{h}\right)+\left(w_{h}, r\right)=0
$$

Where $u_{h}$ and $w_{h}$ nodal elements of $U$ and $W$ respectively so that;

$$
u=u_{h}=\sum_{I=1}^{N} r_{I} \varphi_{I}(x, y) \quad i, j, k \in I
$$

$$
w=w_{h}=\sum_{I=1}^{N} \beta_{I} \psi_{I}(x, y) \quad i, j, k \in I
$$

Where

$\varphi_{I}(x, y)$ and $\psi_{I}(x, y), I=1,2, \ldots, N$ are basis functions in the $x, y$ direction and $\varphi_{I} \neq \psi_{I}$.

Substituting $u_{h}$ and $w_{h}$ as defined in equation (2.31) and (2.32) into equation (2.22) with $w=0$ on $\partial \Omega$ we have:

$$
\sum_{I=1}^{N} \beta_{I} \int_{\Omega}\left[\psi_{I}, \psi_{I, 2}\right] k\left(\sum_{J=1}^{N}\left[\begin{array}{l}
\varphi_{J, 1} \\
\varphi_{J, 2}
\end{array}\right] h_{J}\right) d \Omega+\sum_{I=1}^{N} \beta_{I} \int_{\Omega} \psi_{I} r d \Omega=0
$$

Equation (2.33) can be written as;

$$
\sum_{I=1}^{N} \beta_{I}\left(\sum_{J=1}^{N} K_{I J} H_{J}-R_{I}\right)=0
$$

Where,

$$
K_{I J}=\int_{\Omega}\left[\psi_{I}, \psi_{I, 2}\right] k\left[\begin{array}{c}
\varphi_{J, 1} \\
\varphi_{J, 2}
\end{array}\right] d \Omega
$$

(2.35)

$$
R_{I}=-\int_{\Omega} \psi_{I} r d \Omega
$$

For an arbitrary $\beta_{I}$, it follows that,

$$
\sum_{J=1}^{N} K_{I J} H_{J}=R_{I}, \quad I=1 \ldots N
$$

The following finite element matrix equation given by equation (2.38) holds for any triangular element with nodes $i, j, k$, to a Global equation system;

$$
\frac{K H}{(2.38)}=\underline{R}
$$

A solution for the Hydraulic Heads at the nodes is computed by:

$\underline{K H}=\underline{R}$

(2.39)

$$
\underline{K}^{-1} \underline{K} \underline{H}=\underline{K}^{-1} \underline{R}
$$

$I \underline{H}=\underline{K}^{-1} \underline{R}$

$$
\underline{H}=\underline{K}^{-1} \underline{R}
$$

Where,

$$
\text { (2.42) }
$$

$\underline{H}=$ Vector Matrix contains unknown Hydraulic Heads at the Nodes 
$\underline{R}=$ Vector Matrix containing Potential Head values at the Nodes

$\underline{K}=$ Vector Matrix containing Hydraulic Conductivity values at the Nodes

$$
\left[\begin{array}{lll}
h_{i i} & h_{i j} & h_{i k} \\
h_{j i} & h_{j j} & h_{j k} \\
h_{k i} & h_{k j} & h_{k k}
\end{array}\right]=\left[\begin{array}{lll}
k_{i i} & k_{i j} & k_{i k} \\
k_{j i} & k_{j j} & k_{j k} \\
k_{k i} & k_{k j} & k_{k k}
\end{array}\right]^{-1}\left[\begin{array}{ccc}
r_{i i} & r_{i j} & r_{i k} \\
r_{j i} & r_{j j} & r_{j k} \\
r_{k i} & r_{k j} & r_{k k}
\end{array}\right]
$$

where,

$\begin{array}{lll}h_{i i} & = & \text { Hydraulic Head at Node } 1 \\ h_{i j} & = & \text { Hydraulic Head at Node } 2 \\ h_{i k} & = & \text { Hydraulic Head at Node } 3 \\ h_{j i} & = & \text { Hydraulic Head at Node } 4 \\ h_{j j} & = & \text { Hydraulic Head at Node } 5 \\ h_{j k} & = & \text { Hydraulic Head at Node } 6 \\ h_{k i} & = & \text { Hydraulic Head at Node } 7 \\ h_{k j} & = & \text { Hydraulic Head at Node } 8 \\ h_{k k} & = & \text { Hydraulic Head at Node } 9 \\ k_{i i} & = & \text { Hydraulic Conductivity at Node } 1 \\ k_{i j} & = & \text { Hydraulic Conductivity at Node } 2 \\ k_{i k} & = & \text { Hydraulic Conductivity at Node } 3 \\ k_{j i} & = & \text { Hydraulic Conductivity at Node } 4 \\ k_{j j} & = & \text { Hydraulic Conductivity at Node } 5 \\ k_{j k} & = & \text { Hydraulic Conductivity at Node } 6 \\ k_{k i} & = & \text { Hydraulic Conductivity at Node } 7 \\ k_{k j} & = & \text { Hydraulic Conductivity at Node } 8 \\ k_{k k} & = & \text { Hydraulic Conductivity at Node } 9 \\ r_{i i} & = & \text { Potential Head Value at Node } 1 \\ r_{i j} & = & \text { Potential Head Value at Node } 2 \\ r_{i k} & = & \text { Potential Head Value at Node } 3 \\ r_{j i} & = & \text { Potential Head Value at Node } 4 \\ r_{j j} & = & \text { Potential Head Value at Node } 5 \\ r_{j k} & = & \text { Potential Head Value at Node } 6 \\ r_{k i} & = & \text { Potential Head Value at Node } 7 \\ r_{k j} & = & \text { Potential Head Value at Node } 8 \\ r_{k k} & = & \text { Potential Head Value at Node } 9\end{array}$

$\left[\begin{array}{lll}h_{i i} & h_{i j} & h_{i k} \\ h_{j i} & h_{j j} & h_{j k} \\ h_{k i} & h_{k j} & h_{k k}\end{array}\right]=\left[\begin{array}{lll}a_{i i} & a_{i j} & a_{i k} \\ a_{j i} & a_{j j} & a_{j k} \\ a_{k i} & a_{k j} & a_{k k}\end{array}\right]\left[\begin{array}{ccc}r_{i i} & r_{i j} & r_{i k} \\ r_{j i} & r_{j j} & r_{j k} \\ r_{k i} & r_{k j} & r_{k k}\end{array}\right]$ 
where, $K^{-1}=\left[\begin{array}{ccc}a_{i i} & a_{i j} & a_{i k} \\ a_{j i} & a_{j j} & a_{j k} \\ a_{k i} & a_{k j} & a_{k k}\end{array}\right]$

$\left[\begin{array}{ccc}h_{i i} & h_{i j} & h_{i k} \\ h_{j i} & h_{j j} & h_{j k} \\ h_{k i} & h_{k j} & h_{k k}\end{array}\right]=\left[\begin{array}{ccc}a_{i i} r_{i i}+a_{i j} r_{j i}+a_{i k} r_{k i} & a_{i i} r_{i j}+a_{i j} r_{j j}+a_{i k} r_{k j} & a_{i i} r_{i k}+a_{i j} r_{j k}+a_{i k} r_{k k} \\ a_{j i} r_{i i}+a_{j j} r_{j i}+a_{j k} r_{k i} & a_{j i} r_{i j}+a_{j j} r_{j j}+a_{j k} r_{k j} & a_{j i} r_{i k}+a_{j j} r_{j k}+a_{j k} r_{k k} \\ a_{k i} r_{i i}+a_{k j} r_{j i}+a_{k k} r_{k i} & a_{k i} r_{i j}+a_{k j} r_{j j}+a_{k k} r_{k j} & a_{k i} r_{i k}+a_{k j} r_{j k}+a_{k k} r_{k k}\end{array}\right]$ (3.44)

3.1 Hydraulic Conductivity for Nodal Element

III. ResultsAnd Discussions

Table 3.1Hydraulic Conductivity at Nodes 1-9

\begin{tabular}{ll}
\hline Nodal Element & Hydraulic Conductivity (m) \\
\hline$k_{11}$ & 0.0000001500 \\
$k_{12}$ & 0.0000000099 \\
$k_{13}$ & 0.0000015000 \\
$k_{21}$ & 0.0000042000 \\
$k_{22}$ & 0.0000003900 \\
$k_{23}$ & 0.0000004800 \\
$k_{31}$ & 0.0000000390 \\
$k_{32}$ & 0.0000004200 \\
$k_{33}$ & \\
\end{tabular}

Source: [9]

Table 3.1 gives the values for Hydraulic Conductivities of the corresponding values for Nodal Elements for the calculation of Hydraulic Head.

3.2 Potential Head Values for Nodal Element

Table 3.2 Potential Head Values at Nodes 1-9

Nodal Element Potential Head Value(m)

$r_{11}$

0.0000566237028

0.0000450909162

$r_{12} \quad 0.0000416821155$

$r_{13} \quad 0.0001978052400$

0.0001665966600

$r_{21} \quad 0.0001392123900$

$r_{22} \quad 0.0000196504230$

0.0000174323220

$r_{23} \quad 0.0000146094900$

$r_{31}$

$r_{32}$

$r_{33}$

Source: [9]

Table 3.2 gives the values for Potential Head of the corresponding Nodal Element for the calculation of Hydraulic Head. 


\subsection{Hydraulic Head Values for Nodal Element}

\begin{tabular}{ll}
\multicolumn{2}{l}{ Table 3.3 Hydraulic Head Values at Nodes 1-9 } \\
\hline Nodal Element & Hydraulic Head(m) \\
\hline$h_{11}$ & 40.000 \\
$h_{12}$ & 33.654 \\
$h_{13}$ & 27.861 \\
$h_{21}$ & 35.172 \\
$h_{22}$ & 32.138 \\
$h_{23}$ & 26.345 \\
$h_{31}$ & 33.517 \\
$h_{32}$ & 26.483 \\
$h_{33}$ & 24.828 \\
\hline
\end{tabular}

Table 3.3 gives the result obtained for Hydraulic Head using Table 3.1 and 3.2 in equation (2.45)

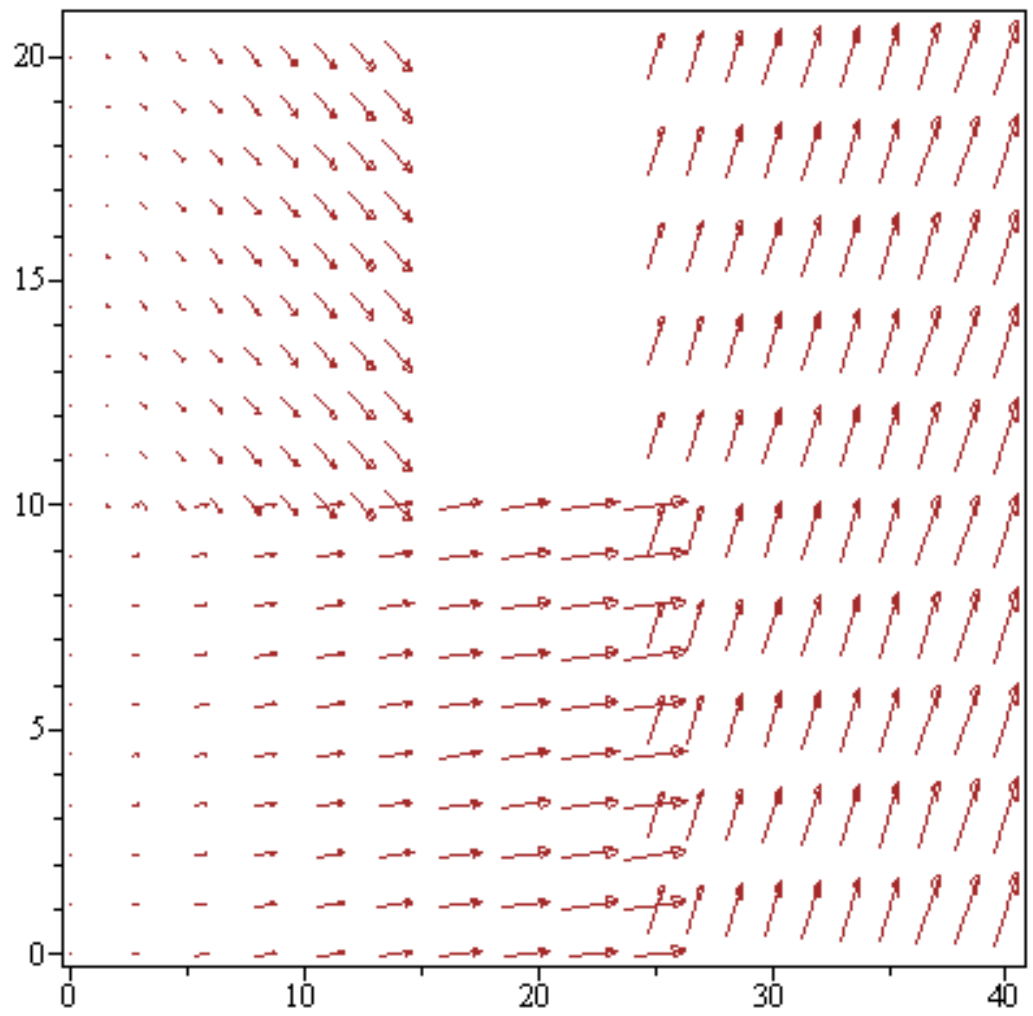

Figure 4.1: Flow Direction Vectors for Hydraulic Head Values

Figure 3.1 represents the Flow Direction Vectors for Hydraulic Head Values obtained in Table 3.3. The arrows give the Recharge and Discharge Directions of the Groundwater Flow.

Table 3.1 gives the values for Hydraulic Conductivities of the corresponding values for Nodal Elements. Table 3.2 gives the values for Potential Head of the corresponding Nodal Element for the calculation of Hydraulic Head. Table 3.3 gives the result obtained for Hydraulic Head using Table 3.1 and 3.2 with equation (3.45). The Flow Direction Vectors for Hydraulic Head Values obtained in Table 3.3 is presented in Figure 3.1. The arrows give the Recharge and Discharge Directions of the Groundwater Flow at each point of the hydraulic head values; $40.000 \mathrm{~m}, 33.654 \mathrm{~m}, 27.861 \mathrm{~m}, 35.172 \mathrm{~m}, 32.138 \mathrm{~m}, 26.345 \mathrm{~m}, 33.517 \mathrm{~m}, 26.483 \mathrm{~m}, 24.828 \mathrm{~m}$. 


\section{Conclusion}

We observed that at hydraulic head values between $40.000 \mathrm{~m}$ and $24.82 \mathrm{~m}$ simulated by the direction vectors show the behavour of groundwater flow as shown in figures 3.1. This means that the water flows from high heads towards the low heads in a semi-circular shape.

\section{References}

[1] S. Jiban, R. K. Somashekar, K. L. Prakashand K. Shivanna, Investigation of heavymetals in crystalline aquifer groundwater from Different valleys of Bangalore, Karnataka, Journal of Geography andRegional Planning, 3(10), 2010, 262-270.

[2] J. Simunek and M. T. Van Genuchten, Contaminant transport in the unsaturated zone: Theory and modeling, in J. W. Delleur (Ed.), Thehandbook of groundwater engineering, $2^{\text {nd }}$ ed., 22(New York: CRC Press, 2006).

[3] J. Simunek, Models of water flow and solute transport in the unsaturated zone, in M. G. Anderson and J. J. McDonnell (Eds.), Encyclopedia of hydrological sciences, 78 (Chichester, England: John Wiley \& Sons, Ltd., 2005) 1171 - 1180.

[4] J. W. Delleur, Elementary groundwater flow and transport processes, in J. W. Delleur (Ed.), The handbook of groundwater engineering , $2^{\text {nd }}$ ed., 3 (New York: CRC Press, 2006).

[5] A. Kamkar-Rouhani, 2D Modelling of groundwater flow using finite element method in an object-oriented approach, in R. Cidu\& F. Frau (Eds.), IMWA symposium 2007: Water in mining environments, Cagliari, Italy, 2007.

[6] P. I. Olasehinde, The groundwaters of Nigeria: A solution to sustainable national water needs, Inaugural Lecture Series 17, Federal University of Technology, Minna, Nigeria, 2010

[7] C. P. Kumar, Groundwater Flow Models, in N. C. Ghosh\& K. D. Sharma (Eds.), Groundwater modeling and management, (New Delhi: Capital Publishing Company, 2006) $153-178$.

[8] T. J. Durbin, Groundwater flow and transport model, Report on Seaside groundwater basin, Monterey County, California, Timothy J. Durbin,Inc., Consulting hydrologists, CA,2007, 45- 48.

[9] A. Idris-Nda, Hydrogeophysical and hydrogeochemical characterization of the Bida Basin aquifer system, doctoral thesis, FederalUniversity of Technology, Minna, Nigeria, 2010. 